\title{
Neurological and skeletal outcomes in 113 patients with closed injuries to the cervical spinal cord
}

\author{
W H Donovan MD, D X Cifu MD, D E Schotte PhD \\ The Institute for Rehabilitation and Research and Department of Physical Medicine and \\ Rehabilitation, Baylor College of Medicine, Houston, Texas, USA.
}

\begin{abstract}
Neurological and skeletal outcomes were evaluated in 113 patients for one year following closed lower cervical spinal cord injuries. The extent of neurological recovery did not depend on surgical versus nonsurgical management, or the degree of spinal angulation, vertebral displacement, spinal stenosis, or inferred mechanism of injury based on the initial plain cervical x-rays. Assessment of skeletal outcomes demonstrated significantly less vertebral angulation, more rapid stabilization, and less anterior callus formation among the patients in the surgical group. In addition, the surgical patients had marginally shorter lengths of hospitalization.
\end{abstract}

Key words: quadriplegia; cervical spinal fusion; spinal cord injury; neurological recovery; spinal stability.

\section{Introduction}

The surgical versus nonsurgical management of closed trauma to the lower cervical spinal cord remains controversial. ${ }^{1-10}$ Whereas surgical fusion usually provides immediate stabilization, attendant risks and complications must be weighed against the nonoperative alternatives. , $11-21^{2}$

The neurological and skeletal outcomes for 113 patients with lower cervical spinal cord injuries managed in 3 trauma centers and one rehabilitation center were evaluated. Lengths of stay, neurological outcomes and skeletal outcomes, including spinal angulation, bony displacement, bony stenosis, callus formation, and spinal instability were assessed.

\section{Material and methods}

\section{Patients}

Patients (94 men and 19 women) were selected from consecutive cases of closed injury to the cervical spine who were admitted within 48 hours of injury to the Texas/South Central Spinal Cord Injury Care System in Houston, Texas, over an 8 year period, from July 1981 through June 1989. All were followed by the authors prospectively from the acute admission for at least one year. The mean age of the patients was 28.6 years $(\mathrm{SD}=13.9)$. The etiologies of injury, the distribution of initial neurological levels and the degrees of incompleteness (Frankel grade) as determined by neurological examination, the skeletal levels of injury and the mechanisms of injury as determined by cervical spine $\mathrm{x}$-ray are shown in Table I.

Forty-eight patients (41 men and 7 women) underwent surgical fusion for the purpose of providing spinal stabilization; 11 by an anterior and 37 by a posterior approach. All posterior fusions employed a wiring technique of 2 or more vertebrae. Only one of the anterior fusions utilized plate fixation. The median time from injury to surgery was 11 days. The interquartile range $(25 \%$ to $75 \%$ of patients operated) was 13.2 days and absolute range was one to 60 days. These procedures were performed for the primary purpose of stabilizing and realigning the cervical spine. While enhancement of neurological function could not be assured, nevertheless in all instances, restoration of the integrity of the neural canal as far as possible, was attempted. Nonsurgical management in 65 patients (57 men and 8 women) consisted of cervical traction (closed reduction, if necessary) and 
Table I Patient characteristics

\begin{tabular}{|c|c|c|c|c|c|c|c|c|}
\hline Etiology & $\begin{array}{c}\text { Motor } \\
\text { vehicle } \\
53(47 \%)\end{array}$ & $\begin{array}{c}\text { Diving } \\
33(29 \%)\end{array}$ & $\begin{array}{c}\text { Falls } \\
16(14 \%)\end{array}$ & $\begin{array}{l}\text { Motor- } \\
\text { cycle } \\
5(4 \%)\end{array}$ & $\begin{array}{l}\text { Sports } \\
5(4 \%)\end{array}$ & $\begin{array}{l}\text { Other } \\
3(3 \%)\end{array}$ & & \\
\hline $\begin{array}{l}\text { Entry neuro- } \\
\text { logical level of injury }\end{array}$ & $\begin{array}{c}\mathrm{C} 2 \\
1(0.9 \%)\end{array}$ & $\begin{array}{c}\mathrm{C} 3 \\
3(3 \%)\end{array}$ & $\begin{array}{c}\mathrm{C} 4 \\
22(19 \%)\end{array}$ & $\begin{array}{c}\text { C5 } \\
38(34 \%)\end{array}$ & $\begin{array}{c}\text { C6 } \\
27(24 \%)\end{array}$ & $\begin{array}{c}C 7 \\
19(17 \%)\end{array}$ & $\begin{array}{c}\mathrm{C} 8 \\
3(3 \%)\end{array}$ & \\
\hline $\begin{array}{l}\text { Entry Frankel } \\
\text { classification }\end{array}$ & $\begin{array}{c}\mathrm{A} \\
71(63 \%)\end{array}$ & $\begin{array}{c}\mathrm{B} \\
30(27 \%)\end{array}$ & $\begin{array}{c}\mathrm{C} \\
12(11 \%)\end{array}$ & $\begin{array}{c}\mathrm{D} \\
(0)\end{array}$ & $\begin{array}{c}E \\
0(0 \%)\end{array}$ & & & \\
\hline Skeletal level of injury & $\begin{array}{c}C 2-3 \\
2(2 \%)\end{array}$ & $\begin{array}{c}\text { C3-4 } \\
10(9 \%)\end{array}$ & $\begin{array}{c}C 4-5 \\
31(27 \%)\end{array}$ & $\begin{array}{c}C 5-6 \\
40(35 \%)\end{array}$ & $\begin{array}{c}\text { C6-7 } \\
3(3 \%)\end{array}$ & $\begin{array}{c}T 1-2 \\
2(2 \%)\end{array}$ & $\begin{array}{c}C 6-7 \\
26(23 \%)\end{array}$ & $\begin{array}{l}\text { C7-T1 } \\
3(3 \%)\end{array}$ \\
\hline $\begin{array}{l}\text { Mechanism of } \\
\text { injury }\end{array}$ & $\begin{array}{c}\text { Flexion/ } \\
\text { distraction } \\
39(35 \%)\end{array}$ & $\begin{array}{c}\text { Flexion/ } \\
\text { compression } \\
30(27 \%)\end{array}$ & $\begin{array}{l}\text { Compression } \\
31(27 \%)\end{array}$ & $\begin{array}{l}\text { Extension } \\
12(11 \%)\end{array}$ & $\begin{array}{c}\text { Shear } \\
1(0.9 \%)\end{array}$ & & & \\
\hline
\end{tabular}

Frankel A - Complete

Frankel B - Incomplete, preserved sensation only

Frankel C - Incomplete, preserved motor/nonfunctional (majority of key muscles below the zone of partial preservation are $<$ Grade 3 )

Frankel D - Incomplete, preserved motor/functional (majority of key muscles below the zone of partial preservation are $>$ or $=$ to Grade 3 )

Frankel E - Complete recovery, may have abnormal reflexes 
maintenance of alignment followed by either SOMI or halo vest immobilization. The contribution to this patient population by 3 trauma centers, staffed by different neurosurgeons and orthopaedic surgeons, accounted for the different approaches to spine trauma. Consequently, some cases with similar injuries were managed differently in the acute period. However, all were followed by one spinal cord rehabilitation specialist, and the medical management of organ systems, other than the spine, followed a single protocol.

\section{Methods}

The length of stay for acute care and rehabilitation, and both the neurological level of injury and the Frankel neurological grade $^{22}$ within the first 48 hours of admission, were determined based on hospital records. The bony level of injury was determined based on inspection of the initial cervical plain $\mathrm{x}$-rays. From this the mechanisms of injury were inferred and grouped using criteria modified from Allen, ${ }^{1}$ into flexion-distraction, flexion-compression, compression, extension, and shear modes. Three, 6 and 12 months neurological and $\mathrm{x}$-ray evaluations were then routinely conducted.

At 3 and 12 months, the extent of vertebral deformity, graded according to Dickson's criteria, ${ }^{23}$ was assessed in terms of millimeters of bony displacement into the spinal cord and accompanying degrees of angulation. Instability and the extent of anterior callus formation were graded using 4 point scales ranging from 'none' to 'marked' ${ }^{24,25}$ The degree of stenosis of the neural canal was measured according to the method shown in Figure 1.

\section{Data analyses}

Data analyses were conducted both to compare groups at the time of injury (eg, age at time of injury, mechanism of injury, etc) and to compare the outcomes resulting from surgical versus nonsurgical management (eg, spinal angulation at 3 and 12 months). In each case, frequency data (eg, mechanism of spinal cord injury or the number of

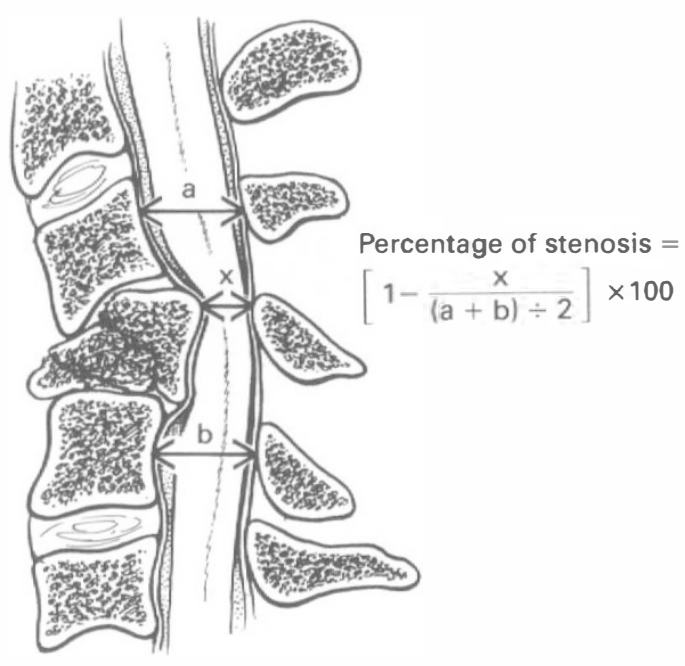

Figure 1 When canal narrowing was observed, the percentage of narrowing (stenosis) was calculated by using an average value of normal canal dimensions above and below the stenosis. The canal diameter at the location of the stenosis divided by the average value gave the fraction of patency. One minus this value gave the fraction of stenosis. This value multiplied by 100 gave the percent of stenosis.

surgical versus nonsurgical patients who had evidence of bony stenosis) were analyzed using $\mathrm{Chi}^{2}$. Ordinal-level variables, for which rank order can be determined but for which the absolute degree of difference between ranks is not known (eg, neurological level or Frankel scores), were analyzed using the Mann-Whitney $U$ test. Data on length of stay were also analyzed using the Mann-Whitney $U$ test. In this case, the Mann-Whitney test, which compares rankordered values rather than absolute values (ie, number of days), was selected to minimize the impact of a small number of patients who had very long hospital stays. Because most of our measures were not made on true interval scales, we also used nonparametric methods (eg, Kendall's tau) to compute correlation coefficients. In contrast, continuous, interval-level variables (eg, age at time of injury) were analyzed using $t$-tests. Although an alpha level of .05 was selected for assessing statistical significance, we also report trends toward significance whenever the $p$ value obtained is 0.1 
or less. The reader should note that such trends could reach significance in larger samples.

\section{Results}

There were no statistically significant differences between the surgical and nonsurgical groups with respect to age, sex, entry, neurological status, degree of vertebral injury and mechanism of injury. There was also no difference between the groups in the extent of comorbidity: that is, despite the fact that injury severity scores (ISS) or abbreviated injury scores (AIS) were not obtained, the authors could not appreciate any difference in the number of patients requiring ventilatory support, chest tube drainage or other intensive care needs between the surgical and nonsurgical patients.

\section{Length of stay}

The mean length of stay on acute and rehabilitation units is shown in Table II for both groups. Although the differences are not statistically significant, there was a trend toward a shorter total length of hospital stay for the surgical group (Mann-Whitney $U=1264, p<.09$ ).

Table II Mean length of stay

\begin{tabular}{lcc}
\hline & Acute & Rehab \\
\hline Surgery & 42.9 & 88.5 \\
No surgery & 47.9 & 99.2 \\
\hline
\end{tabular}

$p<.09$

\section{Skeletal outcomes}

Spinal angulation

The mean spinal angulations in both groups, at 3 and 12 months are shown in Table III. These differences were significant at both 3 (Mann-Whitney $U=985, p<.001$ ) and 12 months (Mann-Whitney $U=1014, \quad p$ $<.001)$.

\section{Bony displacement}

Twenty surgical patients $(42 \%)$ and 37 nonsurgical patients $(57 \%)$ demonstrated some bony displacement. The difference between the groups was not significant (Table III).

\section{Bony stenosis}

Fifty percent of surgical and $85 \%$ of nonsurgical patients demonstrated some bony stenosis on lateral plain or tomographic $\mathrm{x}$-rays at 3 months post injury. The mean of this bony stenosis was $16.1 \%(\mathrm{SD}=14.7 \%)$ and $12.3 \%(\mathrm{SD}=12.4 \%)$ in nonsurgical and surgical patients, respectively. Nonparametric tests revealed that neither the proportions of patients with evidence of stenosis nor the severity of stenosis differed significantly between the 2 groups.

\section{Callus}

The extent of anterior callus formation (excluding those who underwent anterior fusions) is shown in Table IV. Nonparametric analysis revealed a greater proportion of nonsurgical than surgical patients with callus formation at $3\left(\mathrm{Chi}^{2}=12.4\right.$, $p<.01)$ and 12 months $\left(\mathrm{Chi}^{2}=11.0\right.$,

Table III Angulation and displacement at 3 and 12 months

\begin{tabular}{lcccc} 
& \multicolumn{2}{c}{ Angulation (degrees) } & \multicolumn{2}{c}{ Displacement $^{2}$ mm $)$} \\
& 3 months $^{\mathrm{a}}$ & 12 months $^{\mathrm{b}}$ & 3 months $^{\mathrm{c}}$ & 12 months $^{\mathrm{c}}$ \\
\hline Nonsurgical patients & 9 & 9 & 2.4 & 1.8 \\
Surgical patients & $(0-50)$ & $(0-45)$ & $(0-12)$ & $(0-11)$ \\
& 3 & 3 & 2.0 & 1.6 \\
& $(0-21)$ & $(0-23)$ & $(0-20)$ & $(0-19)$ \\
\hline a $p<0.0005$ & & & & \\
b $p<0.0001$ & & & & \\
c $p=$ NS & & & &
\end{tabular}


Table IV A compression of the amount of anterior callus formation after 3 and 12 months between surgical and nonsurgical patients

\begin{tabular}{lcccc} 
& \multicolumn{2}{c}{3 months $^{\mathrm{a}}$} & \multicolumn{2}{c}{12 months } \\
& No surgery & Surgery & No surgery & Surgery \\
\hline None & 21 & 21 & 13 & 16 \\
Minimal & 21 & 14 & 15 & 9 \\
Moderate & 20 & 2 & 12 & 8 \\
Marked & 3 & 0 & 25 & 4 \\
Total & 65 & $37^{\mathrm{c}}$ & 65 & $37^{\mathrm{c}}$ \\
\hline
\end{tabular}

a $p<.01$

b $p<.05$

c Excludes 11 patients who had anterior fusions

$p<.05)$. When patients were grouped according to whether their mechanism of injury involved compression (ie, flexioncompression and compression versus flexion-distraction and extension), nonparametric analysis revealed more callus formation among those with compression mechanisms at 3 months ( $68 \%$ versus $50 \%$; Mann-Whitney $U=1019, p<.01)$ and 12 months ( $80 \%$ versus $60 \%$ : Mann-Whitney $U=995$, $p<.05)$.

\section{Spinal stability}

The extent of spinal instability for both groups is shown in Table V. Only one surgical patient demonstrated minimal instability at 3 months which resolved by 12 months. Among nonsurgical patients, spinal instability was evident in 10 patients (5 minimal, 4 moderate, 1 marked) at 3 months. The 5 with minimal instability all became stable spontaneously over the following 3 months. During that time, external support with a removable orthosis was continued while sitting (or standing). The other 5 with moderate or marked instability were offered late operative fusion; 2 (one marked, one moderate) accepted and were successfully stabilized by posterior fusion and wiring. The 3 who declined surgery remained unstable after 12 months follow up; 2 were subsequently found to have stabilized by 4 years post injury and one patient with moderate instability remains unstable 4 years post injury but is nonetheless asymptomatic. Nonparametric analyses revealed a significant difference in spinal stability between surgical and nonsurgical patients at the 3 month $\left(\mathrm{Chi}^{2}=5.9\right.$,

Table V Instability by no surgery/surgery

\begin{tabular}{|c|c|c|c|c|c|c|}
\hline & \multicolumn{2}{|c|}{ Definition $^{\mathrm{a}}$} & \multicolumn{2}{|c|}{3 months $^{b}$} & \multicolumn{2}{|c|}{12 months $^{\mathrm{c}}$} \\
\hline & $\begin{array}{l}\text { Angulation } \\
\text { (Degrees) }\end{array}$ & $\begin{array}{l}\text { Displacement } \\
(\mathrm{mm})\end{array}$ & No surgery & Surgery & No surgery & Surgery \\
\hline None & 0 & 0 & 53 & 47 & 60 & 48 \\
\hline Minimal & $1-5$ & $1-2$ & 5 & 0 & 1 & 0 \\
\hline Moderate & $6-10$ & $3-4$ & 4 & 1 & 0 & 0 \\
\hline Marked & $>10$ & $>4$ & 1 & 0 & 2 & 0 \\
\hline Total & & & $63^{\mathrm{d}}$ & 48 & $63^{e}$ & 48 \\
\hline
\end{tabular}

\footnotetext{
a After White et al ${ }^{24}$

b $p<.01$

c Nonsignificant $(p>.05)$

${ }^{d}$ Excludes 2 patients whose 3 months $\mathrm{x}$-rays were lost

e Excludes 2 patients, one with marked and one with moderate instability at 3 months, who then had posterior fusion
} 
$p=<.05)$, but not at the 12 month follow up. Five of the 11 patients $(45 \%)$ who had spinal instability at 3 months had sustained flexion/distraction injuries, manifesting the posterior column disruption common to this group. These 5, all nonsurgical patients, had instability classified as marked (1), moderate (3) or minimal (1) and represented $26 \%$ of the nonsurgical group with this type mechanism of injury. When compared with the nondistraction patients in this group, this difference in risk of instability approached significance $\left(\mathrm{Chi}^{2}=6.7, p<.08\right)$ (Table VI).

\section{Neurological outcomes}

Thirty-one percent of surgical patients and $19 \%$ of nonsurgical patients demonstrated improvement in both motor and sensory levels at the one year follow up (Table VII). This difference between the 2 groups was not statistically significant.

Fifty-eight percent of surgical patients and $65 \%$ of nonsurgical patients demonstrated improvement in Frankel classification at the 12 month follow up (Table VIII). Improvement over one year follow up was observed in $17(61 \%)$ of the 28 surgical patients and $23(55 \%)$ of the 42 nonsurgical patients who were initially classified as Frankel A (Tables IX and X, and Figures 2 and 3 ). The differences between the 2 groups with respect to improvement among both complete and incomplete lesions were not statistically significant. Correlational analyses failed to reveal any significant predictors of neurological improvement among any of the variables assessed in this

Table VI A comparison of the amount of instability in nonsurgical patients who sustained flexion-distraction injuries against those who sustained other mechanisms

Amount of Distraction Nondistraction
instability

\begin{tabular}{lrr}
\hline None & 14 & 39 \\
Mild & 1 & 4 \\
Moderate & 3 & 1 \\
Severe & 1 & 0 \\
\hline
\end{tabular}

$p<.08$ study, including mechanism of injury, canal stenosis or, in the surgical group, the time elapsed between the date of injury and the date of surgery. In particular, when the percent of stenosis was correlated with neurological improvement, both segmentally (descent of neurological level) and with regard to long tracts (Frankel grade), significance was reached in neither the surgical nor the nonsurgical group.

\section{Discussion}

This investigation provides comprehensive information on the neurological and skeletal outcomes of patients with spinal cord injury, some of whom were chosen for internal stabilization while others were managed with external devices. Within this system of care, protocols defining medical management were accepted by all physicians. Surgeons differed philosophically, however, over which conditions dictated operative intervention. The decisions to operate were

Table VII A comparison of improvement in neurological level (lowest level with completely normal motor and sensory function) between the initial and 12 month evaluations, among the nonsurgical and surgical groups. (Nonsignificant, $p>.05$ )

\begin{tabular}{lrr}
\hline $\begin{array}{l}\text { Levels of } \\
\text { improvement }\end{array}$ & No surgery & Surgery \\
\hline 0 & 53 & 33 \\
1 & 10 & 13 \\
2 & 2 & 2 \\
Total & 65 & 48 \\
\hline
\end{tabular}

Table VIII A comparison of improvement in Frankel class between the initial and 12 month evaluations, among the nonsurgical and surgical groups. (Nonsignificant, $p>.05$ )

Frankel grade No surgery Surgery
improved

\begin{tabular}{lrr}
\hline 0 & 23 & 20 \\
1 & 16 & 18 \\
2 & 18 & 9 \\
3 & 7 & 1 \\
4 & 1 & 0 \\
Total & 65 & 48 \\
\hline
\end{tabular}


Table IX A comparison of improvement in neurological level and Frankel grade after one year between surgical and nonsurgical patients with initially complete or incomplete lesions (all comparisons nonsignificant, $p>.05$ )

\begin{tabular}{lrrrrrrrrr}
\hline & \multicolumn{3}{c}{ Neurological level } & \multicolumn{3}{c}{ Frankel grade } \\
& \multicolumn{1}{c}{ No surgery } & \multicolumn{2}{c}{ Surgery } & \multicolumn{2}{c}{ No surgery } & \multicolumn{2}{c}{ Surgery } \\
& \multicolumn{1}{c}{ C } & I & C & I & C & I & C & I \\
\hline No improvement & 33 & 20 & 21 & 12 & 17 & 6 & 14 & 6 \\
Improvement & 7 & 5 & 10 & 5 & 23 & 19 & 17 & 11 \\
\hline
\end{tabular}

Table $\mathbf{X}$ Evolution from complete to incomplete lesions between 3,6 , and 12 months post injury in 9 patients who first showed neurological improvement more than 3 months after injury

\begin{tabular}{lccc}
\hline \multicolumn{4}{c}{ Evaluation time } \\
Initial & 3 months & 6 months & 12 months \\
\hline $\mathrm{A}^{1}$ & $\mathrm{~A}$ & $\mathrm{~A}$ & $\mathrm{~B}$ \\
$\mathrm{~A}^{1}$ & $\mathrm{~A}$ & $\mathrm{~A}$ & $\mathrm{~B}$ \\
$\mathrm{~A}^{1}$ & $\mathrm{~A}$ & $\mathrm{~B}$ & $\mathrm{~B}$ \\
$\mathrm{~A}^{1}$ & $\mathrm{~A}$ & $\mathrm{~B}$ & $\mathrm{~B}$ \\
$\mathrm{~A}^{2}$ & $\mathrm{~A}$ & $\mathrm{~B}$ & $\mathrm{~B}$ \\
$\mathrm{~A}^{2}$ & $\mathrm{~A}$ & $\mathrm{~B}$ & $\mathrm{~B}$ \\
$\mathrm{~A}^{2}$ & $\mathrm{~A}$ & $\mathrm{~B}$ & $\mathrm{~B}$ \\
$\mathrm{~A}^{2}$ & $\mathrm{~A}$ & $\mathrm{C}$ & $\mathrm{C}$ \\
$\mathrm{A}^{1}$ & $\mathrm{~A}$ & $\mathrm{C}$ & $\mathrm{C}$ \\
\hline
\end{tabular}

${ }^{1}$ Nonsurgical

${ }^{2}$ Surgical

12 month Frankel grade

\begin{tabular}{|c|c|c|c|c|c|c|}
\hline \multirow{6}{*}{$\begin{array}{l}\text { Entry } \\
\text { Frankel } \\
\text { grade }\end{array}$} & & A & $B$ & C & D & $\mathrm{E}$ \\
\hline & $A$ & 14 & 12 & 4 & 1 & \\
\hline & $B$ & & $\checkmark 5$ & 3 & 5 & \\
\hline & C & & & 1 & 3 & \\
\hline & $D$ & & & & & \\
\hline & $E$ & & & & & \\
\hline
\end{tabular}

Figure 2 Changes in neurological function according to the classification of Frankel et al ${ }^{22}$ at the initial and 12 month evaluation for 48 patients who underwent surgical fusion. The numbers in the boxes to the right of the diagonal line indicate the number of patients who improved, and those on the line indicate the number who remained unchanged.

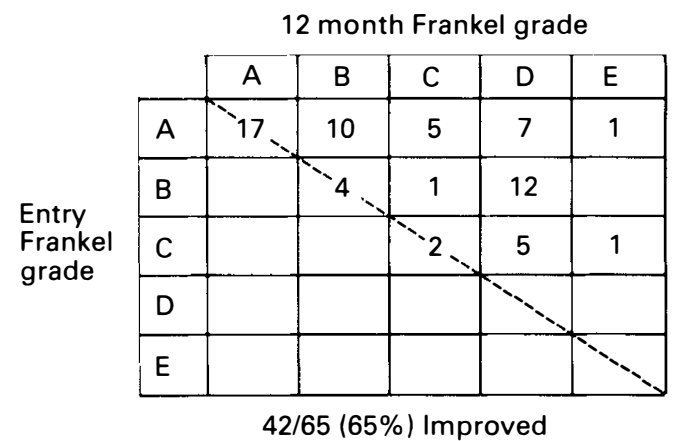

Figure 3 Changes in neurological function according to the classification of Frankel et al ${ }^{22}$ at the initial and 12 month evaluation for 65 patients who were managed nonsurgically, and underwent 'autofusion'. The numbers in the boxes to the right of the diagonal line indicate the number of patients who improved, and those on the line indicate the number who remained unchanged.

based primarily on biomechanical considerations (stability, alignment) rather than preservation of cord function since it was not generally held by all surgeons that operative intervention could influence neurological recovery. The patients were not assigned randomly since universal agreement on a research design, assigning the management of acute spinal injuries acutely in a random fashion, could not be reached in our center. Therefore, this study was initiated so that specific outcomes would be recorded, regardless of the decision to operate or not. Statistical analyses demonstrated no significant differences in demographic, biomechanical or neurological parameters between the 2 groups upon entrance into the study. Comorbidity was also judged by the authors to be evenly 
distributed even though abbreviated injury scores (AIS) or injury severity scores (ISS) were not obtained in a sufficient number of patients.

A review of the literature reveals contrary reports on length of hospitalization in SCI patients. ${ }^{7,10,26}$ In this series, the difference $(10-15 \%)$ approached but did not reach significance $(p<.09)$. Hopefully, this issue will be clarified in the future with a larger sample.

Although minor increases or decreases in angulation over the 12 month period were observed among patients in both groups, those who received surgical fusion achieved better alignment than those who did not. While 2 of the nonsurgical patients were noted to have an angulation of greater than 30 degrees at one year, and retrospectively should have been realigned surgically, the mean angulation of the autofusion group was only 6 degrees greater than the surgical group mean. Therefore, the alignment was acceptable in all but a few cases and while the difference between this group and the surgical group was statistically significant, it was not clinically significant in most cases. Additionally, as noted above, the spinal angulation had no effect on neurological or functional outcome, and produced no apparent complications. These data concur with other reports. ${ }^{3,4}$

Improvements in displacement over the 12 month period were observed among patients in both groups. There was no difference in displacement between surgical and nonsurgical groups and the degree of displacement did not affect neurological improvement over follow up.

Bony stenosis of the neural canal did not show a statistically significant correlation with lack of recovery. This may be explained by the known tendency of the spinal cord to undergo necrosis and myelomalacia at the injury site. ${ }^{27}$ Thus, decompression would not be expected to help. Additionally in such instances, the stenosis would not be 'compressing' an otherwise undamaged cord (as in cervical spondylosis), but rather the bony intrusions into the neural canal are simply juxtaposed to a thin segment of glial tissue or a severely decreased population of cells and axons.
The extent of anterior reactive bone formation in this patient population was greatest in those individuals suffering compression and compression with flexion injuries; however, it occurred with all types of bony injury. Most of the patients who developed anterior callus by 12 months $(72 \%)$ had evidence of it at the 3 month follow up $(60 \%)$, thus the 3 month evaluation may serve as a useful early indicator of eventual callus formation. Nonsurgical management was associated with a statistically significant increase in the presence of callus and the degree of callus achieved. This may be the result of a number of different factors, yet one may postulate that while posterior fusion stimulates the development of bone formation at the operative site (posteriorly), it may limit the impetus for its development anteriorly. Nonetheless, it would appear that since anterior callus was frequently found in patients with posterior fusions $(57 \%$ at 12 months), if operative intervention is planned, posterior fusion alone will still result in a 'two-column' fusion in many patients.

Spinal stability, however, seems to be largely unrelated to callus formation, since it occurred in the majority of the patients in both groups, and its absence, at least on plain radiographs, was noted in many patients who were stable. Of the 11 patients who were noted to have some instability at 3 months post injury, 4 had radiographic evidence of callus formation at that time. Of the 3 patients with spinal instability at 12 months, 2 had radiographic evidence of callus. Regardless, a statistically significant increased risk of developing late instability was found in the nonsurgical group. Six subjects with minimal instability at 3 months were not considered to need late fusion (or refusion in the one case from the surgical group), and all ultimately became stable even though 2 progressed to the moderate instability level at 6 months before stabilizing at 12 months. The 5 patients with moderate or marked instability were felt to need surgical stabilization, but only 2 agreed. Two of the remaining 3 ultimately stabilized sometime after 12 months and one continues to have moderate instability but is nonetheless asymptomatic. $\mathrm{He}$ is now 4 
years post injury. While the question as to how much instability to 'accept' is not precisely answered in this study, those with only minimal instability at 3 months, regardless of initial management, can probably be safely observed since they will likely all stabilize spontaneously with continued external support.

The greatest risk for late instability appeared within the group who sustained flexion-distraction injuries. All patients who developed more than 'minimal' instability were from this group. Roughly one in 4 of these patients, if managed conservatively, will not be stable at 3 months. Therefore, as also suggested by others, ${ }^{2.3,8}$ it would seem that a desire to avoid this risk, along with the desire to progress the patient through rehabilitation as efficiently as possible, would influence the management decision in favor of surgical stabilization for flexiondistraction injuries.

Improvement in neurological functioning was found to be independent of such factors as surgery, including the time from injury to surgery, spinal deformity, mechanism of bony injury, and narrowing of the neural canal. These findings support the works of earlier investigations. ${ }^{3,4,7,10,28-30}$ Since some improvements were noted in some patients in both groups, factors other than those analyzed, such as the initial impact force, patient management during the first 24 to 48 hours, or preexisting anatomic relationships of the cervical spine, may be more important in determining the degree of neurological recovery rather than the type of stabilization employed, the morphology of the bony injury, or the proximity to anatomical reduction. Improvement was noted, as expected, in those patients entering the treatment system who had incomplete spinal lesions, but was also found in patients in both the surgical and nonsurgical groups who initially had 'complete' lesions. In fact, of the 71 initially complete patients, 40 $(56.3 \%)$ gained some neurological function over the next year, and of these 40,9
$(22.5 \%)$ did not begin to show improvement until after the first 3 months. Others have reported similar results and discussed the difficulties that may interfere with ascertaining the true completeness of the lesion acutely. ${ }^{29}$ These include impairments of the sensorium, ${ }^{31}$ inexactness or incomplete recording of the neurological examination, and the inability of that examination to test all tracts within the spinal cord. ${ }^{32}$ While these factors could certainly explain why some patients in both groups moved from complete lesions (Frankel A) to incomplete lesions when only the initial and one year examinations are considered, it cannot explain why 9 (5 nonsurgical, 4 surgical) patients were noted to move from Frankel A to incomplete lesions (Frankel B and C) when the 3 month and one year examinations are compared. Two of these patients (nonsurgical) were found to change from a Frankel A to Frankel B between the 6 month and 12 month exams (Table $\mathrm{X}$ ).

\section{Conclusion}

These data demonstrate that in lower cervical spine injuries, while surgical stabilization results in better initial and one-year skeletal alignment and stability, and a minor decrease in acute and rehabilitation hospital lengths of stay, it offers no advantage over nonsurgical stabilization in terms of the initial and one-year neurological outcomes and the majority of skeletal outcomes, with the major exception being stability in injuries with flexion-distraction mechanisms.

\section{Acknowledgments}

This work was supported in part by the United States Department of Education's National Institute on Disability and Rehabilitation Research Spinal Cord Injury Model Demonstrations Grant H133N00016. Grateful acknowledgement is given to Francine Mechoulam, Tulio Soto, and Lubor Jarolimek for assistance with data collection.

\section{References}

1 Allen BL Jr, Ferguson RL, Lehmann TR et al (1982) A mechanistic classification of closed, indirect fractures and dislocations of the lower cervical spine. Spine 7: 1-27. 
2 Bucci MN, Dauser RC, Maynard FA, Hoff JT (1988) Management of post-traumatic cervical spine instability: operative fusion versus halo immobilization. Analysis of 49 cases. J Trauma 28: 1001-1006.

3 Bucholz RD, Cheung KC (1989) Halo vest versus spinal fusion for cervical injury: evidence from an outcome study. J Neurosurg 70: 884-892.

4 Donovan WH, Kopaniky D, Stolzmann E, Carter RE (1987) The neurological and skeletal outcome in patients with closed cervical spinal cord injury. J Neurosurg 66: 690-694.

5 Holdsworth F (1970) Fractures, dislocations, and fracture-dislocations of the spine. J Bone Joint Surg 52A: 1534-1551

6 Meyer PR, Jr (1988) Surgery of Spine Trauma. Churchill Livingstone, New York.

7 Murphy KP, Opitz JL, Cabanela ME, Ebersold MJ (1990) Cervical fractures and spinal cord injury: outcome of surgical and nonsurgical management. Mayo Clin Proc 65: 949-959.

8 Osti OL, Fraser RD, Griffiths ER (1989) Reduction and stabilization of cervical dislocations. An analysis of 167 cases. J Bone Joint Surg 71B: 275-282.

9 Sonntag VKH, Hadley MN (1988) Nonoperative management of cervical spine injuries. Clin Neurosurg 34: 630-649.

10 Tator CH, Duncan EG, Edmonds VE, Lapczak LI, Andrews DF (1987) Comparison of surgical and conservative management in 208 patients with acute spinal cord injury. Can J Neurol Sci 14: 60-69.

11 Aebi M, Mohler J, Zach GA, Morscher E (1986) Indication, surgical technique, and results of 100 surgically-treated fractures and fracture-dislocations of the cervical spine. Clin Orthop 203: 244-257.

12 Apuzzo MLJ, Heiden JS, Weiss MH, Ackerson TT, Harvey JP, Kurze T (1978) Acute fractures of the odontoid process. An analysis of 45 cases. J Neurosurg 48: 85-91.

13 Chan RC, Schweigel JF, Thompson GB (1983) Halo-thoracic brace immobilization in 188 patients with acute cervical spine injuries. $J$ Neurosurg 58: 508-515.

14 Dunn ME, Seljeskog EL (1986) Experience in the management of odontoid process injuries: an analysis of 128 cases. Neurosurgery 18: 306-310.

15 Ekong CEU, Schwartz ML, Tator CH, Rowed DW, Edmonds VE (1981) Odontoid fracture; management with early mobilization using the halo device. Neurosurgery 9: 631-637.

16 Glaser JA, Whitehill R, Stamp WG, Jane JA (1986) Complications associated with the halo-vest. A review of 245 cases. J Neurosurg 65 : 762-769.

17 Johnson RM, Hart DL, Simmons EF, Ramsby GR, Southwick WO (1977) Cervical orthoses. A study comparing their effectiveness in restricting cervical motion in normal subjects. J Bone Joint Surg 59A: 3323-39.

18 Johnson RM, Owen JR, Hart DL, Callahan RA (1981) Cervical orthoses. A guide to their selection and use. Clin Orthop 154: 34-45.

19 Maiman DJ, Larson SJ (1982) Management of odontoid fractures. Neurosurgery 1982: 11: 471-476.

20 Watts C: Comment on Maiman DJ, Barolat G, Larson SJ (1986) Management of bilateral locked facets of the cervical spine. Neurosurgery 18: 547.

21 Whitehill R, Richman JA, Glaser JA (1986) Failure of immobilization of the cervical spine by the halo vest: a report of five cases. J Bone Joint Surg 68A: 326-332.

22 Frankel HL, Hancock DO, Hyslop G, Melzak J, Michaelis LS, Ungar GH (1969) The value of postural reduction in the initial management of closed injuries of the spine with paraplegia and tetraplegia. Paraplegia 7: 179-192.

23 Dickson JH, Harrington PR, Erwin WD (1978) Results of reduction and stabilization of the severely fractured thoracic and lumbar spine. J Bone Joint Surg 60A: 799-805.

24 White AA, Johnson RM, Panjabi MM, Southwick WO (1975) Biomechanical analysis of clinical stability in the cervical spine. Clin Orth Rel Res 109: 85-96.

25 White AA, Southwick WO, Panjabi MM (1976) Clinical instability in the lower cervical spine: a review of past and current concepts. Spine 1: 15-27.

26 Cotler HB, Cotler JM, Alden ME, Sparks G, Biggs CA (1990) The medical and economic impact of closed cervical spine dislocations. Spine 15: 448-452.

27 Kakulas BA, Bedbrook GM (1976) Pathology of injuries of the vertebral column - with emphasis on the macroscopical aspects. In: Vinken PJ, Bruyn GW, editors. Handbook of Clinical Neurology. North Holland Publishing Company, Amsterdam: 27-42.

28 Flynn TB (1982) Neurologic complications of anterior cervical interbody fusion. Spine 7: 536-539.

29 Heiden JS, Weiss MH, Rosenberg AW et al (1975) Management of cervical spinal cord trauma in Southern California. J Neurosurg 43: 732-736.

30 Wagner FC Jr, Chehrazi B (1982) Early decompression and neurological outcome in acute cervical spinal cord injuries. J Neurosurg 56: 699-705.

31 Maynard FM, Reynolds GG, Fountain S, Wilmot C, Hamilton R (1979) Neurological prognosis after traumatic quadriplegia. Three-year experience of California Regional Spinal Cord Injury Care System. $J$ Neurosurg 50: 611-616.

32 Dimitrijevic MR, Faganel J (1985) Motor control in the spinal cord. In: Eccles J, Dimitrijevic MR, editors. Recent Achievements in Restorative Neurology: 1. Upper Motor Neuron Functions and Dysfunctions. S Karger, Basel: 150-162. 